\title{
Perceptions on Genetic and Genome Screening among College Students in the Emirates of Abu Dhabi
}

\author{
Habiba Alsafar a,b,c Deema Islayem ${ }^{a}$ Reem Almansoori ${ }^{a}$ Tahnoon Alnahyan ${ }^{a}$ \\ Abdulla Alhammadi ${ }^{d}$ Raven Haan ${ }^{c}$ Guan Tay ${ }^{a, b, c}$ \\ ${ }^{a}$ Center for Biotechnology, Khalifa University of Science and Technology, Abu Dhabi, United Arab Emirates; \\ ${ }^{b}$ Department of Biomedical Engineering, Khalifa University of Science and Technology, Abu Dhabi, United Arab \\ Emirates; 'College of Medicine and Health Sciences, Khalifa University of Science and Technology, Abu Dhabi, \\ United Arab Emirates; ${ }^{\mathrm{d} D e p a r t m e n t}$ of Mechanical Engineering, Khalifa University of Science and Technology, Abu \\ Dhabi, United Arab Emirates
}

\section{Keywords \\ Genetic testing $\cdot$ Genetics $\cdot$ Knowledge $\cdot$ Attitude $\cdot$ Ethic}

\begin{abstract}
Introduction: Genetic testing is playing a greater part in contemporary medical practice. The ability of high throughput and parallel detection of variants that could predict the possibility of developing genetic diseases and to deliver personalized health care for individuals is slowly but most certainly gaining traction. This study was conceived to investigate the knowledge level and degree of awareness among youth in the United Arab Emirates, on the role of genetic testing in society, and the delivery of health care. Methods: Data from individuals were collected, and statistical analyses were performed to assess whether or not there were differences in people's attitude toward genetic testing, depending on variables such as age, gender, and prior knowledge of genetic testing. Volunteers were recruited at the main campus of Khalifa University in Abu Dhabi via walk-ins to the recruitment desk or via an email which was circulated to both the
\end{abstract}

staff and student population of the university. The survey that was circulated through email was also shared with friends and family, and through social media, to try to capture a larger and more diverse demographic population. $\boldsymbol{R} \boldsymbol{e}$ sults: Results found that most of the participants were aware of genetic testing and showed a positive attitude toward the technology. However, there was an apparent lack of knowledge and understanding of regarding certain genetic concepts, such as the alternate sources of obtaining genetic information other than blood samples. The mean knowledge score was $6.3 \pm 1.9$ out of 9 , and mean attitude score was 3.6 \pm 1.3 out of 6 . The main factors that affected knowledge and attitude were gender and prior knowledge of genetic testing. Conclusion: This study used surveys as an effective tool to evaluate the general knowledge of genetic testing of the general public. It is recommended to embed genetic topics in schools and universities to further increase people's awareness regarding genetic testing.

(c) 2021 The Author(s).

Published by S. Karger AG, Basel karger@karger.com www.karger.com/dmj

Karger $\frac{V}{\%}$

BOPEN ACCESS
C) 2021 The Author(s)

Published by S. Karger AG, Basel

This is an Open Access article licensed under the Creative Common Attribution-NonCommercial-4.0 International License (CC BY-NC) (http://www.karger.com/Services/OpenAccessLicense), applicable to the online version of the article only. Usage and distribution for commercial purposes requires written permission.
Correspondence to:

Habiba Alsafar, habiba.alsafar@ku.ac.ae 


\section{Introduction}

The use of genetic testing and genomic screening has rapidly been gaining traction in medical practice to provide personalized care to individual patients $[1,2]$. Data from genetic tests can identify genetic variants that directly or indirectly predispose one to disease. In addition to providing information to the medical field for personalized medicine, genetic testing also has important implications in the forensic sciences field [3]. A primary goal of national genetic research programs is to invest in the compilation of genetic data to develop ethnic genetic testing programs that can be used to personalized medicine and treatment plans, based on the genetic makeup and ethnic distribution of the population of a country [4]. To achieve this goal, patients must be informed about medical decisions that are made on the basis of the results of genetic testing [5]. In order to implement a nationwide genetic screening program, the ultimate decision to take action on the basis of a particular test relies on both the patient's understanding of genetics and inheritance, and their attitudes toward genetic testing.

There are several methods used in genetic testing laboratories, such as karyotyping and the genotyping. Karyotyping is a chromosome-based technique that looks for abnormal numbers or structures of chromosomes resulting in genetic conditions. This technique is commonly used to detect trisomy in individuals, in which the additional chromosome manifests in disease, such as Down syndrome, Patau syndrome, and Edwards syndrome. Genetic variants can be identified through molecular tests that focus on either specific genes or DNA fragments, to identify variants, duplications, or deletions at the DNA level that could lead to genetic disorders and disease [5].

In addition to the use in forensic testing, and for the detection of disease-causing genetic variants, genetics can also be used for a wide range of applications including paternity testing and histocompatibility testing for transplant matching. More frequently, it is now being used as a proactive measure, such as in prenatal investigations to determine and evaluate the risk of a baby inheriting a genetic or chromosomal disorder [6], or in diagnostic testing for DNA variants that cause disease, before symptoms of the disorder manifest in a patient. These proactive tests make it possible to take preemptive measures that may delay or even prevent the onset of undesirable symptoms of disease [7]. However, genetic testing also has limitations and risks [8]. The risk level of procedures depends on how the genetic sample is obtained; for example, the collection of a maternal blood sample poses no risk to the fetus, whereas obtaining an amniotic fluid sample for prenatal testing carries a minor risk for miscarriage $(0.35 \%)$ [9].

In the past, the level of knowledge regarding genetics and genetic testing has found to be generally low in various populations $[10,11]$. However, this has been changing in recent years, with the emergence and popularity of at-home genetic testing kits, targeted for individuals to purchase to conduct their own genetic tests in the comfort of their home [12]. Although there is an increased consumer demand for personal genomic testing, suggesting a positive attitude toward genetic screening, there appears to still be a slight lack of understanding, with a mean overall comprehension score of $79.1 \%$ reported in a study of individual's understanding of their genetic results [12]. Although this is a relatively high overall comprehension, this shows that still over $20 \%$ of the information was not understood, and that awareness and understanding can still be increased. In addition, these comprehension scores were lower for understanding results on specific genetic carriers, suggesting a need for further public education [12]. There does appear to be an appreciation of basic concepts of genetics and the idea that it can be inherited from one generation to another. However, there is a lack of the deep understanding of the topic. This can be attributed to a number of factors that affect our knowledge of genetics in different cultures, demographics, and education levels. Although a number of studies in the past $[10,11,13]$ have shown limited knowledge of genetics in the general public, other more recent studies have stated that public attitude or perception toward genetic testing is positive [14]. Genetic development is viewed as having potential advancements and advantages in the future of medicine and health care [15]. However, there have been some concerns raised in areas, such as parental testing [16]. Ethical concerns have always been raised as an issue, in the context of potential social and emotional side effects from test results. Research studies conducted among Muslim communities have reported generally positive attitudes toward genetic testing for diagnosis and management of diseases; however, these studies have also highlighted cultural constraints toward certain aspects of genetic testing, for example, the abortion of a fetus diagnosed with a genetic defect [17]. Despite substantial progress in genetic testing and genome analysis, the Arab region remains relative novices with respect to these technologies. This could be explained by a number of different factors, including the perspectives of the Muslim culture, the legal framework, the availability of financial resources to invest in preventative health care, and the priorities of govern- 
ment policies [17]. Islamic scriptures provide guidance regarding some of the outcomes of these tests, such as the views on abortion unless it will endanger the mother life, in vitro fertilization, cloning, and genetic engineering. These acts are viewed as forbidden (Haram), since it involves the creation or detractions of living creatures and potential souls [18]. Nevertheless, barring these acts, genetic testing and genomic analysis are not forbidden in the United Arab Emirates (UAE), and applications are reviewed and managed by health agencies of the country and some emirates [16].

Public awareness campaigns to disseminate accurate information on technology are of primary importance. It can be useful in promoting and even accelerating the implementation to enroll subjects for genome projects, whether they are for research or clinical applications, in Muslim-dominant countries. The lack of knowledge on the techniques and usage of results from genetic testing leads to misconceptions, unwarranted fear, and rejection of technologies on the prejudicial beliefs. Every aspect of education plays a key role since attitudes toward genetic testing are hugely influenced by religious, cultural, and moral views $[17,19]$.

Data on the genome of ethnic groups of Arabs and those who reside or originate from the Greater Middle East region are limited. A recent audit of genome data in the public domain showed that only a mere $0.8 \%$ is from people who originate from this region [20]. It is clear that there are phenotypic differences, of which the genome plays an important role. Consequently, studies on each ethnic group to provide the data on specific variants and their association with disease are important to allow meaningful results from genetic testing [20].

Genome technology has only started becoming readily available in the Greater Middle East in the recent decade. There are several genome projects in the Gulf region, specifically in Saudi Arabia, Kuwait, Qatar, and the UAE, all focusing on investigating the genetic makeup of individuals and populations that are indigenous to the region [21$24]$. Because of the importance of genomic technology in modern biomedical research and medical practice, the use of such technology has been and continues to be integrated into the health sector, especially in the Kingdom of Saudi Arabia. It is useful for providing essential data to reduce the transmission of genetic diseases by allowing individuals to make informed choices. It is also expected to improve health-care services for affected patients [21]. A leading program in the KSA, known as King Abdulaziz City for Science and Technology, collaborates with different international genetic institutes with the goal of im- proving health-care services in the KSA. King Abdulaziz City for Science and Technology is linked to hospitals such as King Faisal Specialist Hospital and Research Center, the core facility of the Saudi Human Genome project. The DNA sequencing efforts focus on diseases that are commonly diagnosed in populations of the region, such as cancer, obesity, and diabetes. Other neighboring countries have also invested in genome projects. Kuwait completed a recent study by sequencing an individual's genome as part of the initiative genome program that studied asthma and obesity [22]. The Qatar Genome Program was established to develop a database to combine wholegenome sequences and other data including comprehensive phenotypic data gathered at Qatar Biobank [23]. The data collected are intended to help in health-care management including future plans for the use of genomic data for medicine in Qatar. Screening programs for diseases such as homocystinuria, the population's most common genetic disorder, will continue to grow.

The UAE has genetic screening programs for diseases such as Thalassemias $[25,26]$; however, genome-scale testing has yet to be implemented, despite a number of initiatives currently under consideration. Recently, a proposal to sequence 1,000 UAE genomes was proposed and the first 2 genome sequencing of Emirati citizens were published [24]. This UAE genome project aims to sequence the genome of UAE citizens using next-generation sequencing technology [24]. A database is proposed to assist with the identification of rare genetic variants in the UAE population, as well as improving the understanding of the molecular and genetic association with common diseases in the Arabian region, such as diabetes and cardiovascular disease [24]. Data will be used to develop early detection systems and national programs for prevalent diseases in the UAE [24]. The population in the UAE is diverse; among nearly 11 million residents in the country, only around $10 \%$ are UAE nationals [24]. The remainder of the population is comprised of immigrants from different countries such as Yemen, Oman, Iran, Egypt, South Asia (including India, Bangladesh, and Pakistan), and Europe [24, 27]. This creates a unique gene pool that consists of different ethnic groups, along with genetic variants that predispose the population to diseases. However, genetic testing is not readily available to the health-care system. There is and will continue to be a high demand for genome data and eventually the need for geneticists and counselors to develop the infrastructure required to improve the health care of individuals in the region. 
This study was developed to investigate both the genetic knowledge and attitudes toward genetic testing among the UAE population. It is important to consider perceptions of the public in the implementation of any health program in the context of the privacy and usage of personal data for clinical and research use, as well as ensuring that individuals are not discriminated against due to their genetic testing results, for example, in cases where insurance companies may withhold medical converge for treatment of people whose genetic testing reveals possible disorders [28].

\section{Materials and Methods}

\section{Subjects}

This study surveyed 565 subjects residing in UAE to assess their genetic knowledge and attitude toward genetic testing. A diverse range of participants (different backgrounds, genders, ages, and employment statuses) responded to the survey. The study was approved by the Institutional Review Board of Khalifa University of Science and Technology (H19-006). Subjects were only allowed to participate in the survey after they approved and signed a consent form. The consent form included information about the aim of the study, and the questions were not set to be mandatory, so the participants could opt out of any question. Throughout the study, the identities of each participant were kept anonymous. To be eligible to participate in the study, participants had to be above 18 years old. Participants who answered questions, but were below the age of 18 , were excluded from the study, resulting in 529 participants. Since the participants had the choice to answer any question, the total number of participants in each question varied.

The subjects were recruited at different events that occurred at the main Abu Dhabi campus of Khalifa University of Science and Technology, and an online survey was prepared and sent to subjects by email and social media platforms (e.g., WhatsApp), where the survey questions were attached in the Appendix. This ensured that subjects were not only students and staff at Khalifa University, but were from a wider pool of individuals. The goal of the survey was to determine the level of knowledge subjects had on genetics and their views and attitudes regarding their right to genetic testing. Therefore, the survey questions covered different topics and were divided into 3 parts: (1) demographic-based questions (gender, age, employment status, awareness of genetic testing, and family history of genetic disease), (2) 9 questions on genetic knowledge, and (3) 6 questions on attitudes toward genetic testing.

\section{Statistical Analysis}

Data were analyzed statistically after exporting responses from the online survey Web site to a Microsoft ${ }^{\circledR}$ Excel sheet. All the data were categorical, so it was analyzed first by frequencies and percentages. The questions were divided into 3 parts: (1) general questions, (2) questions on genetic knowledge, and (3) questions pertaining to attitudes toward genetic testing. The number of participants who answered each question was counted. The aim of this study was to evaluate the knowledge of people and their attitudes toward genetics in general and the process of genetic testing, spe-
Table 1. Demographic data showing the percentage and number of participants $(n)$ who responded to the survey

\begin{tabular}{lc}
\hline Variables & $n(\%)$ \\
\hline Gender & \\
Female & $362(68.4)$ \\
Male & $167(31.6)$ \\
Age & \\
$18-24$ & $417(78.8)$ \\
$25-35$ & $72(13.6)$ \\
$36-50$ & $29(5.5)$ \\
50 and above & $11(2.1)$ \\
Current employment status & \\
Employed & $77(14.6)$ \\
Retired & $3(0.6)$ \\
Student & $420(79.5)$ \\
House duties/housewife & $11(2.1)$ \\
Unemployed & $17(3.2)$ \\
Heard about genetic testing & \\
Yes & $343(65)$ \\
No & $151(28.7)$ \\
Did not know & $33(6.3)$ \\
Family history of genetic disease & \\
Yes & $215(40.8)$ \\
No & $218(41.4)$ \\
Did not know & $94(17.8)$ \\
\hline
\end{tabular}

cifically. Therefore, the responses of participants for these 2 outcome variables (knowledge and attitude) were analyzed. With respect to genetic knowledge questions, a score of 1 was assigned for correct answers, and score of 0 was assigned for incorrect and "Don't know" answers. Regarding attitudes toward genetic testing questions, a score of 1 was assigned for positive attitude answers, and score of 0 was assigned for negative attitude and "Don't know" answers. For each participant, total knowledge and attitude scores were calculated by summing across the questions with scores ranging from 0 to 9 and $0-6$, respectively. Since these data for knowledge and attitude were continuous, the mean and standard deviation were calculated for each demographic variable. To determine the association between the demographic variables (gender, age, current employment status, knowledge of genetic testing, and family history of genetic disease) with (knowledge and attitude) variables, a $T$ test and one-way ANOVA were performed. The $T$ test was used when comparing 2 groups, while one-way ANOVA was used when comparing $>2$ groups. A $p$ value of $<0.05$ was considered statistically significant. Finite population correction factor was used to correct the $p$ value that resulted for 2 variables (gender and employment status).

\section{Results}

Among 529 participants, 362 were female (68\%) and 167 were male (32\%) (Table 1). The majority of participants $(78.8 \%)$ were students with an age range of $18-24$ years. The 
Table 2. Number and percentage of participants who answered the 9 genetic knowledge questions correctly and incorrectly, in addition to those who did not know the answer

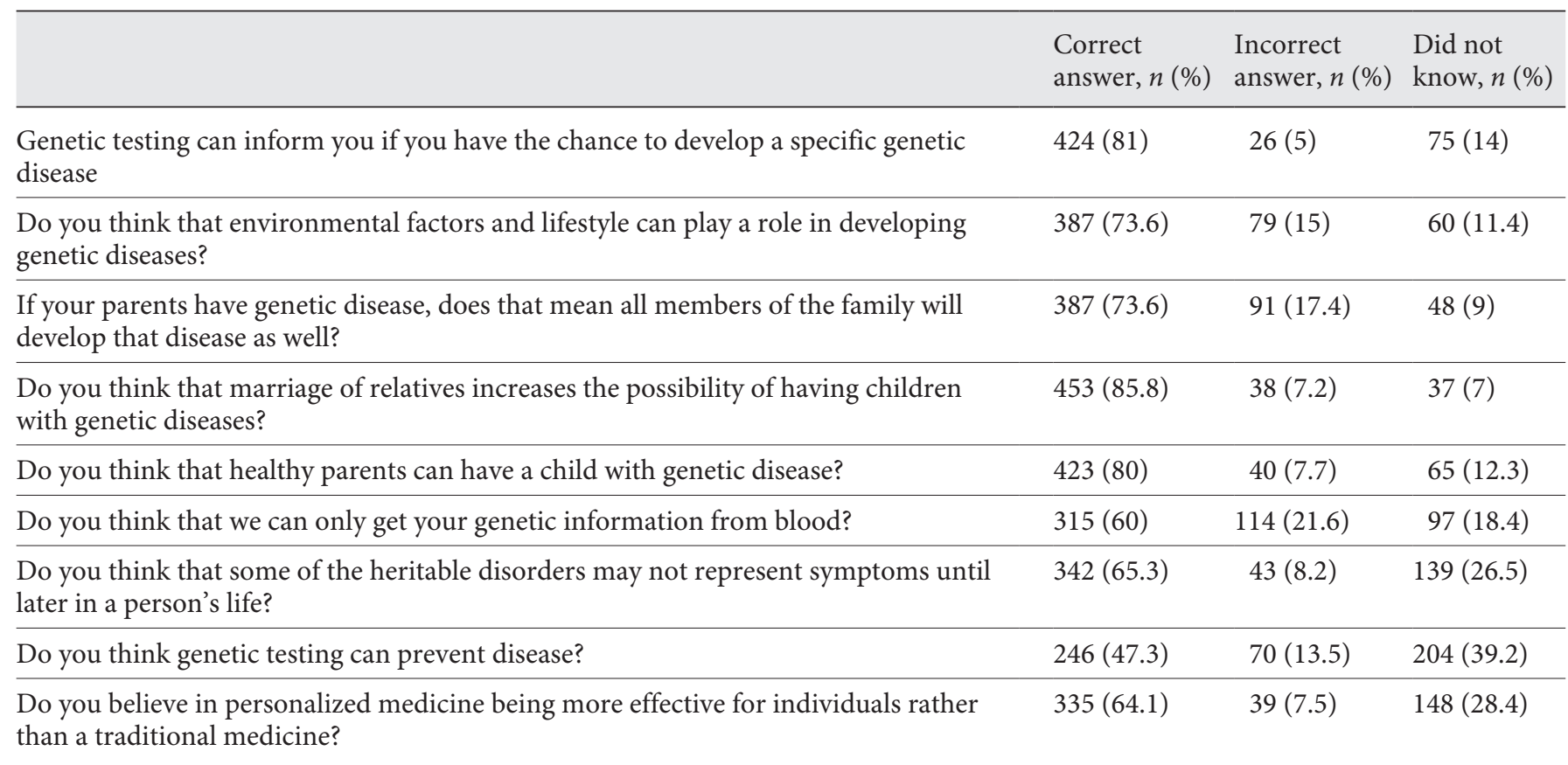

remaining participants were of different age-groups above 24 years old. Employment status of the participants was distributed according to the following: student $(78.8 \%)$, employed (14.6\%), retired (0.6\%), housewife (2.1\%), and unemployed (3.2\%). The participants who had heard about genetic testing constituted $65 \%$ of the sample, and $35 \%$ had not previously heard of the technology or had no knowledge of the technology. The number of participants who reported having a family history of genetic disease was nearly equal to those who did not had a history, with percentages of $40.8 \%$ and $41.4 \%$, respectively. The remainder (17.8\%) of the participants reported that they did not know if they had a family history of genetic disease.

The response of the participants to the 9 knowledge questions is shown in Table 2. Most of the participants answered correctly to the questions concerning the nature of genetic disease, with a percentage range from $73 \%$ to $85 \%$. However, there was some misunderstanding in relation to personalized medicine and characteristics of genetic diseases revealed by the questions "Do you believe in personalized medicine being more effective for individuals rather than a traditional medicine?" and "Do you think that some of the heritable disorders may not represent symptoms until later in a person's life?", respectively, as only $64.1 \%$ and $65.3 \%$ answered correctly, demonstrating a lack of under- standing in these areas in over a third of the population sample. In addition, less than half of the participants answered correctly that genetic testing could potentially prevent disease, and 39.2\% did not know the answer. In a similar downward trend, only $21.6 \%$ of the participants provided incorrect answers to the question "Do you think that we can only get your genetic information from blood?". These responses showcase that there are still some areas of genetic testing that are not fully or even well-understood by individuals from our sample, despite the majority of individuals being educated university students.

The response of the participants to the 6 attitude questions is shown in Table 3. A majority of participants (80\%) believed in the importance of genetic testing and supported the use of the technology if it resulted in improved treatments. Further, $73 \%$ of the participants agreed with taking genetic tests, while only $11 \%$ and $16 \%$ disagreed or were unsure, respectively. However, approximately $40 \%$ of the participants believed that genetic testing could potentially cause more harm than good to the society. Most of the participants (60\%) agreed with the use of their genetic testing results for further genetic research. On the other hand, there were different opinions regarding sharing the genetic results with patient's relatives, in which $37.7 \%, 48.7 \%$, and $13.6 \%$ agreed, disagreed, or were unsure, respectively. 
Table 3. Percentages of participants who agreed, disagreed, and were unsure regarding the 6 questions that were about attitude toward genetic testing

\begin{tabular}{|c|c|c|c|}
\hline & $\begin{array}{l}\text { Agree, } \\
n(\%)\end{array}$ & $\begin{array}{l}\text { Disagree, } \\
n(\%)\end{array}$ & $\begin{array}{l}\text { Don't know, } \\
n(\%)\end{array}$ \\
\hline Do you believe in the importance of genetic testing such as sequencing for newborn baby? & $419(79.5)$ & $50(9.5)$ & $59(11)$ \\
\hline Do you believe that genetic testing will cause more harm than good to the society? & $116(22)$ & $309(59)$ & $98(19)$ \\
\hline $\begin{array}{l}\text { Would you take a genetic test if it resulted in you having improved treatments (such as } \\
\text { medications with less side effects)? }\end{array}$ & $411(78.8)$ & $43(8.2)$ & $68(13)$ \\
\hline $\begin{array}{l}\text { Do you think that medical specialists have the right to use the genetic results of any patient } \\
\text { for further genetic research? }\end{array}$ & $313(59.5)$ & $126(24)$ & $87(16.5)$ \\
\hline $\begin{array}{l}\text { Do you think that medical specialists have the right to share genetic results with a patient's } \\
\text { relatives? }\end{array}$ & $196(37.7)$ & $253(48.7)$ & $71(13.6)$ \\
\hline
\end{tabular}

The association between demographic data and total genetic knowledge is shown in Table 4. The mean knowledge score was $6.3 \pm 1.9$ out of 9 . Female participants $(6.4 \pm 1.7)$ had significantly greater knowledge than male $(5.9 \pm 2.3)$ $(p<0.05)$. Furthermore, the participants who had heard about genetic testing $(6.8 \pm 1.6)$ had significantly greater knowledge than those who had not previously heard of the technology $(5.3 \pm 2.1)(p<0.001)$. On the other hand, the age of participants and their current employment status, as well as having a family history of genetic disease, did not significantly alter the participants' genetic knowledge, with the mean knowledge score of $6.3 \pm 1.9$.

The association between demographic data and attitude toward genetic testing is shown in Table 4 . The mean attitude score was $3.6 \pm 1.3$ out of 6 . Female participants $(3.7 \pm 1.3)$ showed a significantly more positive attitude than males $(3.3 \pm 1.5)(p<0.05)$. Furthermore, previous knowledge about genetic testing before was significantly associated with the positive attitude toward genetic testing ( $p<0.001$ ). Responses to genetic knowledge, the age of participants, their current employment status, and a family history of genetic disease were not significantly associated with the participant's attitude toward genetic testing.

\section{Discussion/Conclusion}

Recent advancements in genetic testing have and will continue to advance medical practice. The way people form opinions and garner acceptance toward genetic testing relies, at least to some extent, on their knowledge and attitude regarding genetic testing technologies [10].
There have only been a small number of studies that have explored the extent to which knowledge of genetics is distributed throughout the population and attitudes toward genetic testing in the UAE. As such, it is important to further investigate the attitudes toward genetic testing in the UAE, to better understand and try to address any negative attitudes, and to help further progress in national screening programs. As such, the aim of this study was to estimate the extent of knowledge and attitudes of residents in the UAE toward genetic testing and to assess the extent to which UAE residents appreciate their rights regarding the technology. In general, the results showed a relatively high knowledge among the participants of the study and more positive attitudes toward genetic testing as compared to previous studies undertaken on this subject [15]. A study in 2015 on the effectiveness of premarital screening in the UAE demonstrated that the mandatory screening programs were unsuccessful at discouraging at-risk marriages; however, over $85 \%$ of participants in our study agreed that the marriage of relatives increases the risk of having a child with a genetic disease [17]. This suggests that attitudes toward genetic testing are also improving over time, as well as awareness about specific risk factors such as consanguinity, that have been widely ignored in the past in this region [17]. The factors in our study that were found to affect knowledge and attitude toward genetic testing were gender and prior knowledge of genetic testing. These findings are significant and relevant to the advancement of genetic screening programs in the UAE, as it highlights the importance of implementing educational information regarding genetic testing. 
Table 4. Association of demographic data with total genetic knowledge and attitudes toward genetic testing, where the association is determined by $p$ values determined by $T$ test and one-way ANOVA

\begin{tabular}{|c|c|c|c|c|}
\hline \multirow[t]{2}{*}{ Variables } & \multicolumn{2}{|l|}{ Knowledge $^{\mathrm{a}}$} & \multicolumn{2}{|l|}{ Attitudes ${ }^{b}$} \\
\hline & mean $\pm \mathrm{SD}$ & $p$ value & mean $\pm S D$ & $p$ value \\
\hline \multicolumn{5}{|l|}{ Gender } \\
\hline Female & $6.4 \pm 1.7$ & \multirow{2}{*}{0.011} & $3.7 \pm 1.3$ & \multirow{2}{*}{0.003} \\
\hline Male & $5.9 \pm 2.3$ & & $3.3 \pm 1.5$ & \\
\hline \multicolumn{5}{|l|}{ Age } \\
\hline $18-24$ & $6.2 \pm 1.9$ & \multirow{4}{*}{0.359} & $3.6 \pm 1.3$ & \multirow{4}{*}{0.357} \\
\hline $25-35$ & $6.3 \pm 2.1$ & & $3.6 \pm 1.5$ & \\
\hline $36-50$ & $6.9 \pm 1.9$ & & $4.0 \pm 1.4$ & \\
\hline 50 and above & $6.3 \pm 1.8$ & & $3.5 \pm 1.5$ & \\
\hline \multicolumn{5}{|l|}{ Current employment status } \\
\hline Employed & $6.5 \pm 1.9$ & \multirow{5}{*}{0.543} & $3.7 \pm 1.4$ & \multirow{5}{*}{0.069} \\
\hline Retired & $5.7 \pm 2.5$ & & $5.3 \pm 0.6$ & \\
\hline Student & $6.2 \pm 1.9$ & & $3.6 \pm 1.3$ & \\
\hline House duties/housewife & $6.6 \pm 1.5$ & & $4.0 \pm 1.3$ & \\
\hline Unemployed & $6.6 \pm 1.3$ & & $4.1 \pm 1.2$ & \\
\hline \multicolumn{5}{|l|}{ Heard about genetic testing } \\
\hline Yes & $6.8 \pm 1.6$ & \multirow{3}{*}{$<0.001$} & $3.9 \pm 1.2$ & \multirow{3}{*}{$<0.001$} \\
\hline No & $5.3 \pm 2.1$ & & $2.9 \pm 1.4$ & \\
\hline Don't know & $5.2 \pm 2.4$ & & $3.3 \pm 1.4$ & \\
\hline \multicolumn{5}{|c|}{ Family history of genetic disease } \\
\hline Yes & $6.3 \pm 1.8$ & \multirow{3}{*}{0.658} & $3.6 \pm 1.3$ & \multirow{3}{*}{0.556} \\
\hline No & $6.3 \pm 1.9$ & & $3.6 \pm 1.4$ & \\
\hline Don't know & $6.1 \pm 2.3$ & & $3.7 \pm 1.4$ & \\
\hline
\end{tabular}

The mean knowledge score in the whole study is $6.3 \pm 1.9$ out of 9 . The mean attitude score in the whole study is $3.6 \pm 1.3$ out of $6 . \mathrm{SD}$, standard deviation. ${ }^{\text {a }}$ The total score of genetic knowledge is $9 .{ }^{\mathrm{b}}$ The total score of attitude toward genetic testing is 6 .

The level of knowledge among UAE residents in this study was higher than some previous studies conducted in other countries throughout the world $[10,15,29]$, which again reinforces the importance of continued curriculum in schools in the UAE covering genetic testing. Compared to a similar study conducted in Jordan, only $77 \%$ of university individuals were familiar with the term genetic testing [29], whereas $81 \%$ of our subjects were aware of the implications of genetic testing, suggesting a slightly higher knowledge base of genetic testing in the UAE. However, it is hard to compare results, as the sets of questions used were different between their survey and ours. Similarly, their subjects were not representative of the entire Jordanian public and consisted of only educated university students. Our results might be influenced by the nature of the participants, in which the majority were young, educated, university students, and nearly twothirds of the subjects were females. This limitation of the study highlights the importance of further investigations with a larger, more diverse sample size. These characteristics coincided with the high knowledge found previously in a Saudi study [30]. As expected, there was a significantly high association between prior awareness of genetic testing and knowledge on the topic. Those who had heard about genetic testing before showed greater knowledge than those who did not. On the other hand, employment status and age-group did not significantly affect the knowledge of genetic testing, even though they displayed high knowledge scores. It was essential to apply finite population correction factor to correct $T$ test and oneway ANOVA values of the gender and employment status, to ensure that the $p$ values were correct and did not result from the fact that the survey was distributed to a certain demographic (mostly female university students). Therefore, this term takes into account circumstance, where the central limit theorem and standard error of estimate do not apply. It basically accounts for capturing the difference between sampling with and without re- 
placement. After multiplying the value found for the finite population correction factor with the standard errors of the 2 variables mentioned before, the results stayed the same, suggesting that the results were initially accurate.

The participants demonstrated a high level of knowledge regarding the nature of genetic diseases, in which the percentages ranged between $74 \%$ and $86 \%$. The questions that were revealed by this concept were about the possibility for genetic diseases to be inherited from parents to children, whether the parents were healthy or carriers for the genetic disease, and the factors influencing development of genetic diseases, such as environment and lifestyle. These findings showed that participants in general, and especially students, who constitute 3 quarters of the study, received very high levels of education in the UAE and had strong foundation knowledge of the basics of genetics, since the concept behind these questions is taught in high schools. Furthermore, the vast majority of participants were aware of marriage of relatives which might lead to negative consequences in offspring developing genetic diseases. This result is optimistic despite the fact that consanguineous marriage is still high in UAE. It shows that the youth today are becoming more educated and are aware of the risks of marrying relatives, as it might cause birth defects and further genetic diseases. Cousins share one-eighth of their genes; thus, the probability that their children might develop the same gene copies from both parents is $1 / 16$. This results in a heightened chance of inheriting genetic disease among the offspring. Generally, the reasoning behind the marriage of relatives goes back to local traditions, in addition to social, cultural, psychological, and religious values in families. However, the results of this study suggest that the educated youth of the UAE are becoming more aware of the risks of consanguinity, which will hopefully reduce genetic disease prevalence in the UAE, as the prevalence of consanguineous marriages decreases due to awareness. This is something that is currently being tackled in the UAE with mandatory genetic screening and counseling being conducted in all new marriages between Emiratis [16].

Although results showed a high knowledge among participants regarding certain genetic concepts, there was a misunderstanding regarding other concepts. For example, only $65 \%$ of the participants knew that it is not necessary for genetic disorders to represent its symptoms in childhood; instead, they are not expressed until later in the affected individual's life, and 26.5\% reported that they did not know the answer to this question and $8 \%$ answered it incorrectly. The question of personalized medicine being more effective for individuals rather than tra- ditional medicine was proposed to find out if people are up to date on new methods in genetics. Personalized medicine plans are used for categorizing various people into separate groups in order to provide them with appropriate medicine plans that are tailored individually, based on their predicted diseases or health issues. Acceptance of personalized medicine was predominant, $64 \%$ of subjects agreed it was more effective, and only $7.5 \%$ disagreed. Knowledge toward sources of samples for genetic testing was more limited, with $<$ two-thirds of the participants knowing that it is possible to get genetic information from other sources than blood, while the remaining participants thought that blood was the only source for genetic information. Blood testing is the most common diagnostic test for health-care systems to determine biochemical and physiological information, and most people regardless of their age have had this test performed several times. Therefore, it seems that people have not been exposed to other methods, as most individuals will only experience a blood test unless they suffer from diseases that require more extensive testing.

Surprisingly, $81 \%$ of the participants knew that genetic testing can inform them if they have the chance to develop a specific genetic disease; however, less than half of the participants knew that genetic testing can prevent disease, despite these 2 questions being related. Genetic testing can provide early detection of a disease, so that they can follow a treatment or disease management plan to either delay the disease or prevent it entirely. Therefore, it is suggested that there was some misunderstanding or confusion regarding the understanding of the question, as approximately $40 \%$ of participants reported that they did not know the answer.

In the attitude section regarding genetic testing, a relatively positive attitude was found in the collected data. A mean attitude of $3.6 \pm 1.3$ out of 6 was calculated. A large number of participants regarded genetic testing for sequencing newborn babies to be important with $79.5 \%$ agreeing to it. Although genetic sequencing of a newborn baby can potentially avoid future health issues, parents are making decisions that their child might strongly disagree with later on in their life; such a matter is sensitive in a way of taking the individual agency or decision-making. An overall favorable attitude was observed toward genetic testing being valuable for preventing diseases and providing future treatments, with $78.8 \%$ or participants displaying a positive response. Genetic testing allows patients to better manage their health care and avoid unnecessary checkups or other forms of tests, such as screening. Moreover, it can direct a person toward available moni- 
toring, prevention, and treatment options. A reporting percentage of $59 \%$ disagreed that genetic testing causes more risks and side effects than benefits, which shows a general positive attitude toward the overall benefits of genetic testing, suggesting that most participants support the progress and advancement in the medical field. A concern is raised for the question regarding medical specialists having the right to share a patient's personal medication history or background with their relatives. This is concerning on an ethical level, and although $37 \%$ of participants had no problems in terms of trust, respect, and privacy of their information, the majority disagreed with this question, suggesting patients being aware of their rights to privacy. Finally, a large number of participants agreed to the question of medical specialists carrying further genetic testing studies with their results, which means that the majority of the participants are unaware of their rights in the medical field, as patients have to approve and permit medical specialists to use their results in further testing, only a percentage of $24 \%$ disagreed to this question.

The study presented has several limitations. First is the reporting nature of the questionnaire, as it was based on self-reporting, in which participants read the questions themselves and then answered it independently. This may cause reporting issues when they do not understand the question, as it could result in them answering randomly. Although the questions constructed were based on previous validated studies and the supervision of an expert professor, another limitation is language barriers, as although the majority of UAE citizens speak English, there was a minority that could not participate due to language limitations. The next step would be having another version of the survey conducted and distributed in Arabic. Another limitation was the limited subject source; participants were mostly students and only a few faculty members, and members from outside the Khalifa University community took part. Thus, the limited sample of mostly university students is not representative of the entire UAE population. Further limitation taken into consideration is the educational background of the participants. Some of them are students who came from science, technology, engineering and mathematics (STEM) majors, which can introduce bias in terms of having more knowledge than the general populations. In addition, the majority of the population were from UAE which means the results are limited because the participants came from the same region, so they had similar beliefs and values. Last, due to time restrictions, the sample size was only around 566. To improve the reliability of the results, more participants could have taken part over a longer period of time.

The incredible advancements and results from genetic testing in recent years have enabled the technology to gradually integrate itself into medical practice. Therefore, it is important to understand the level of knowledge and attitudes of the society toward genetics and genetic testing. The current study shows clear evidence of a relatively high level of knowledge of genetics among a subset of UAE residents, although a number of participants lacked an appreciation of their rights in relation to research, when confronted with some of the fundamental concepts of genetics such as ethics behind genetic testing. The overall results showed a mostly positive attitude toward genetic testing among participants. The next step would be to expand the survey to allow for more participants, refine the questions, and work with focus groups in order to enhance the findings of this survey. The results from the study would suggest that it is important to promote information on genetics and testing technologies nationwide, with topics on the subject being taught at schools, and international conferences on the subject hosted in the country. Awareness of genetics can be disseminated via social and traditional media with the aid of educational videos to reach wider populations. Our findings suggest that with the proper understanding of the basic concepts of genetics, there will be an improvement and increase of positive attitudes and knowledge base.

\section{Acknowledgments}

We thank the participants of the study for their generosity in completing the survey.

\section{Statement of Ethics}

The study was approved by the Institutional Review Board of Khalifa University of Science and Technology, reference number H19-006. Written informed consent has been obtained from all of the participants to participate in the study.

\section{Conflict of Interest Statement}

The authors have no conflicts of interest to declare.

\section{Funding Sources}

No funding was received for this study. 


\section{Author Contributions}

H.A. and G.T. conceived the study. D.I. and R.A. developed and carried out the survey assays. T.A. and A.A. were responsible for recruitment of the volunteer contributed data to the study. R.H. cleaned the data, and with D.I. and R.A., analyzed, constructed the figures, and wrote the first draft of the manuscript. H.A. and G.T. provided critical review during manuscript preparation. All authors on the primary list contributed to the data interpretation or critically reviewed the manuscript and approved the final manuscript for submission.

\section{Data Availability Statement}

The data that support the findings of this study are not publicly available due to containing information that could compromise the privacy of research participants but are available on request from the corresponding author.

\section{References}

1 Haile L. Making personalized medicine a reality. Genet Eng Biotechnol News. 2008;28(1): $1-3$.

2 Gray SW, Hicks-Courant K, Lathan CS, Garraway L, Park ER, Weeks JC. Attitudes of patients with cancer about personalized medicine and somatic genetic testing. J Oncol Pract. 2012;8(6):329-35.

3 Arenas M, Pereira F, Oliveira M, Pinto N, Lopes AM, Gomes V, et al. Forensic genetics and genomics: much more than just a human affair. PLoS Genet. 2017;13(9):e1006960.

4 Elhaik E, Tatarinova T, Chebotarev D, Piras IS, Maria Calò C, De Montis A, et al. Geographic population structure analysis of worldwide human populations infers their biogeographical origins. Nat Commun. 2014; 5(3513):3513-2.

5 Wapner RJ, Martin CL, Levy B, Ballif BC, Eng $\mathrm{CM}$, Zachary JM, et al. Chromosomal microarray versus karyotyping for prenatal diagnosis. N Engl J Med. 2013;367(23):2175-84.

6 Lippman A. Prenatal genetic testing and screening: constructing needs and reinforcing inequities. Am J Law Med. 1991;17(17): $15-50$.

7 Sandler S, Alfino L, Saleem M. The importance of preventative medicine in conjunction with modern day genetic studies. Genes Dis. 2018;5(2):107-11.

8 Heshka JT, Palleschi C, Howley H, Wilson B, Wells PS. A systematic review of perceived risks, psychological and behavioral impacts of genetic testing. Genet Med. 2008;10(1):1932.

9 Beta J, Lesmes-Heredia C, Bedetti C, Akolekar R. Risk of miscarriage following amniocentesis and chorionic villus sampling: a systematic review of the literature. Minerva Ginecol. 2018;70(2):215-9.
10 Molster C, Charles T, Samanek A, O'Leary P. Australian study on public knowledge of human genetics and health. Public Health Genomics. 2008;12(2):84-91.

11 Jallinoja P, Aro AR. Knowledge about genes and heredity among Finns. New Gen Soc. 1999;18(1):101-10.

12 Ostergren JE, Gornick MC, Carere DA, Kalia SS, Uhlmann WR, Ruffin MT, et al. How well do customers of direct-to-consumer personal genomic testing services comprehend genetic test results? Findings from the impact of personal genomics study. Public Health Genomics. 2015;18(4):216-24.

13 Genetic Alliance. Understanding genetics: a New York, Mid-Atlantic guide for patients and health professionals. Washington, DC: Genetic Alliance; 2009

14 Udesky L. The ethics of direct-to-consumer genetic testing. Lancet. 2010;376(9750):1377-

15 Etchegary H, Cappelli M, Potter B, Vloet M, Graham I, Walker M, et al. Attitude and knowledge about genetics and genetic testing. Public Health Genomics. 2010;13(2):80-8.

16 Saffi M, Howard N. Exploring the effectiveness of mandatory premarital screening and genetic counselling programmes for $\beta$-thalassaemia in the Middle East: a scoping review. Public Health Genomics. 2015;18(4) 193-203.

17 A-Aqeel-Al . Ethical guidelines in genetics and genomics. An Islamic perspective. Saudi Med J. 2005;26(12):1862-70.

18 Smith L. Human genetics and Islam: scientific and medical aspects. J IMA. 2011;43(2): 83-90.

19 Lerman C, Daly M, Masny A, Balshem A. Attitudes about genetic testing for breast-ovarian cancer susceptibility. J Clin Oncol. 1994; 12(4):843-50.

20 Popejoy AB, Fullerton SM. Genomics is failing on diversity. Nature. 2016;538(7624): $161-4$.
21 Research and Development [Internet]. Kacst. edu.sa. 2019 [cited 2019 Apr 4]. Available from: https://www.kacst.edu.sa/eng/RD/pages/content.aspx? $\mathrm{dID}=62$

22 Thareja G, John SE, Hebbar P, Behbehani K, Thanaraj TA, Alsmadi O. Sequence and analysis of a whole genome from Kuwaiti population subgroup of Persian ancestry. BMC Genomics. 2015;16(1):92.

23 Qatar Genome Program. Qatar genome; 2019. Available from: https://qatargenome. org.qa/.

24 Al-Ali M, Osman W, Tay GK, AlSafar HS. A 1,000 Arab genome project to study the Emirati population. J Hum Genet. 2018;63(4): 533-6.

25 Baysal E. Hemoglobinopathies in the United Arab Emirates. Hemoglobin. 2001;25(2): $247-53$.

26 Kim S, Tridane A. Thalassemia in the United Arab Emirates: why it can be prevented but not eradicated. PLoS One. 2017;12(1): e0170485.

27 United Arab Emirates Population [Internet]. Worldpopulationreview.com. 2019 [cited 2019 Apr 05]. Available from: http://worldpopulationreview.com/countries/united-arab-emirates-population/.

28 Beyleveld D, Brownsword R. Human dignity, human rights, and human genetics. Mod Law Rev. 1998;61(5):661-80.

29 Altaany Z, Khabour OF, Al-Taani G. Knowledge, beliefs, and attitudes concerning genetic testing among young jordanians. J Multidiscip Healthc. 2019;12:1043-8.

30 Olwi D, Merdad L, Ramadan E. Knowledge of genetics and attitudes toward genetic testing among college students in Saudi Arabia. Public Health Genomics. 2016;19(5):260-8. 